\title{
A theoretical exploration: Zone of Proximal Development as an ethical zone for teaching mathematics
}

\author{
Yasmine Abtahi, University of South East Norway (Norway)
}

\begin{abstract}
A theoretical exploration: Zone of Proximal Development as an ethical zone for teaching mathematics

Abstract

For decades, Vygotsky's Zone of Proximal Development (ZPD) has been utilized as an important theoretical framework for exploring and analysing the concept of learning, but its implications for teachers remain much less explored. In this article, I conceptualise some of the roots of Vygotsky's sociocultural theory of learning and, on this basis, I explore the ZPD as an ethical and powerful zone for teaching. Together with providing a thorough description of some key aspects of Vygotsky's theoretical concepts, the major question stated, What are the ethical responsibilities of teachers to guide students do mathematics that is beyond their independent ability? intends to open up an original line of inquiry. I first give an overview of this learning theory, as it stemmed from Marxism, my means of supporting examples from mathematics education research literature. It follows a discussion on the issue of ethics and responsibility to more explicitly highlight the ethical responsibilities and power of teachers that are implicit in the concept of ZPD.
\end{abstract}

Keywords. ZPD; power; ethics; responsibilities; mathematics learning and teaching. máticas

Una exploración teórica: La Zona de Desarrollo Próximo como zona ética para enseñar mate-

Resumen

Durante décadas, la Zona de Desarrollo Próximo (ZDP) de Vygotsky se ha utilizado como un importante marco teórico para explorar y analizar el concepto de aprendizaje, pero sus implicaciones para el profesorado permanecen mucho menos exploradas. En este artículo, conceptualizo raíces de la teoría sociocultural del aprendizaje de Vygotsky y, a partir de aquí, exploro la ZDP como una zona ética y poderosa para la enseñanza. Junto con ofrecer una intensa descripción de aspectos claves de conceptos teóricos de Vygotsky, la principal pregunta enunciada, ¿Cuáles son las responsabilidades éticas del profesorado al guiar a los alumnos a hacer matemáticas que están más allá de sus habilidades independientes? pretende abrir una línea original de estudio. Empiezo con una perspectiva general de esta teoría del aprendizaje y de sus orígenes en el Marxismo mediante ejemplos de la investigación en educación matemática. Sigo con una discusión sobre cuestiones de ética y responsabilidad a fin de señalar más explícitamente las responsabilidades éticas y el poder del profesorado implícitas en el concepto de ZDP.

Palabras clave. ZDP; poder; ética; responsabilidades; aprendizaje y enseñanza de matemáticas.

\section{Context}

The Zone of Proximal Development (ZPD) is an integral part of Vygotsky's sociocultural theory of learning, which explains how learning and development is the result of social and cultural influences. The ZPD is described by Vygotsky as "the distance between the actual developmental level (independent problem solving) and the level of potential development (problem solving under adult guidance or in collaboration with more capable peers)" (Vygotsky, 1978, p. 69). In mathematics education and mathematics education research, the concept of ZPD has received much attention in the better understanding of the concept of learning (Roth, 2018), for two reasons: 
1. its explicit reference to the need for the presence of another more competent person; and

2. its implicit requirement of having mediational things - tools and signs, including language, signs, symbolisms, mathematical tools, tools of technology, and more (Abtahi et al., 2017; Walshaw, 2017).

In this article, I portray an image of the concept of ZPD, within Vygotsky's theory, and explain its theoretical underpinning as it relates to learning and mathematics learning. Then I highlight the concept of ZPD as it connects to the teaching of mathematics. Together with providing a thorough description of some key aspects of Vygotsky's theoretical concepts, through the major question stated, What are the ethical responsibilities of teachers to guide students do mathematics that is beyond their independent ability, the article intends to open up an original line of inquiry. While I will be putting important weight on the role of the teachers, and their ethics and responsibility in children's ZPDs, this will not be at the expense of the role of the peers as both teachers and peers will have a role in the examples of illustration of ZPD that will be provided. In what comes, I will be using and intersecting two discourses, one that is mostly theoretical and one that introduces examples and more practice-based ideas. In order to connect both discourses, I select and elaborate the examples in connection to theoretical insights presented in the first sections of the article.

\section{Method}

I used conceptual analysis as a method for this article. Conceptual analysis is a method for philosophical and more theoretical inquiry, which entails "analysing a term or concept, showing its multiple uses and meanings, for the primary purpose of clarification" (Burbules \& Warnick, 2006, p. 491). My utilization of conceptual analysis is primarily and critically theoretical, and contains an important philosophical component in how it inquires into the meanings of and arguments around concepts. I attempt to clarify the ZPD concept as it is already conceptualised and used in the field of mathematics education, as a theory of learning. The first part of the article is more descriptive, while the second part is a more normative than descriptive endeavor, in which I attempt to investigate the power and ethical responsibilities of teachers according to the ZPD and its meanings. The second part therefore is a theoretical investigation into how the concept of ZPD could be used as a powerful zone for teaching, and not a description of how it is actually used.

No concept is an independent entity in the vacuum. Concepts grow and develop in webs of relationships with other concepts, and hence exist within a network that provides a more comprehensive picture. Vygotsky developed the concept of ZPD in a network of other concepts. In this respect, it is important to know Vygotsky's context at a personal level, so as to better understand the roots and dimensions of his theory in the concept of learning and ZPD, and more importantly, at least in the context of this article, in the concept of teaching.

Vygotsky lived and worked in Russia. He developed his theory in the years of the growth of Socialism in Russia and specifically during the October Socialist Revolution of 1917. He worked during the German occupation of the First World War, and until the Bolshevik (Communist) victory in 1919. Throughout, he was not only an educational theorist and psychologist, but also an active participant in major social transformation under Bolshevik rule (Yasnitsky \& Van der Veer, 2015), before he passed away at the young age of 37. Like all of us, Vygotsky was influenced by the events and 
circumstances of his surroundings, both the physical and material events of wars and revolutions and by the philosophical concepts that had been introduced by Marx and Engels. More specifically, his legacy is influenced by Marx and Engels' (1930/1988) belief that, in any action, "[i]t is not only the material of my activity — like the language itself, which the thinker uses - which is given to me as a social product. My own existence is a social activity" (p. 11). Although this proposition had been echoed by many others, Vygotsky was the first to attempt to understand and conceptualize Marx and Engels' views in the human psychological, and later in the educational, realm (Cole et al., 1978).

In close relation to Marxism and Marx and Engels' view to issues of learning and development, Vygotsky produced his socio-cultural theory, with concepts of ZPD, mediation of signs and tools, and internalization as its building blocks. By assembling and connecting all these building blocks together, it is possible to make sense and meaning of the ZPD concept as well as to investigate its potential implications for both mathematics learning and mathematics teaching. Figure 1 shows the network of concepts that $\mathrm{ZPD}$ is part of.

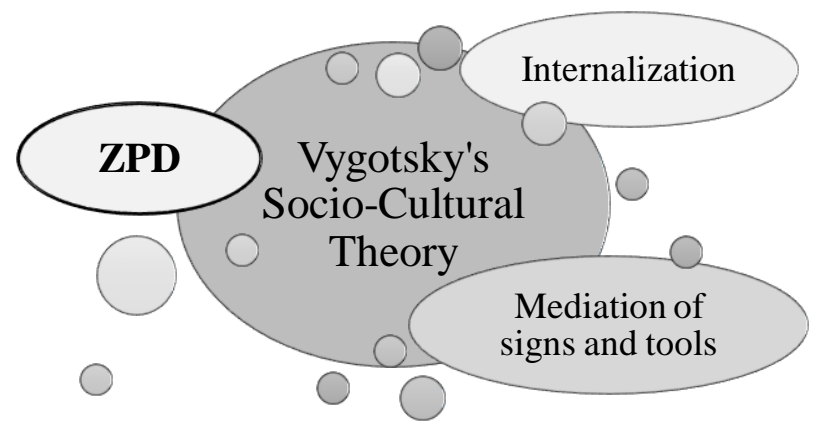

Figure 1. Network of concepts or the building blocks for the ZPD concept

In the following, I discuss the connection between Vygotsky's theory and Marx and Engels' view that our own existence is a social activity in process, as it relates to the ZPD. I present my discussion in two distinct parts regarding learning and teaching. I do so because I believe that Vygotsky's theory of learning has been conceptualized and used for decades, but its ethics for teaching have received rather limited attention. To investigate the demands of ZPD for teachers and particularly mathematics teachers, I ask: What are the ethical responsibilities of teachers to guide students do mathematics that is beyond their independent ability?

\section{Part 1 - Vygotsky, Learning and Learners}

One can envisage a significant stretch from Marx and Engels' belief that our "own existence is a social activity" to details of classrooms, teaching and learning. To manage this stretch, Vygotsky (1978) proposed that the construction of one's higher mental functions (e.g. logical memory, voluntary attention, learning of school subjects including mathematics) lie outside the individual and instead occupy a social plane. He stated that "any function in the child's cultural development appears twice, or on two planes. First, it appears between people as an inter-psychological category, and then within the child as an intra-psychological category" (Vygotsky, 1978, p. 163). This claim is in line with Marx and Engels' view that our "own existence is a social activity". Our becoming, our very existence, occurs through and within interaction with others. Vygotsky does not leave his statement at the surface level; beyond claiming that somehow children learn 
and develop in and through the process of interactions with others, he formulates an inherent connection between the two developmental planes of the individual and the social. This inherent connection is made by the presence of the two mediating agents of signs and tools in general; and more specifically in the context of learning, by the presence of more knowledgeable others. In the next subsection, I elaborate on the mediational signs, tools and the more knowledgeable others, as they are conceptualized by Vygotsky and his followers and interpreters.

\subsection{Presence of signs and tools}

Vygotsky sees the linkage between the individual and the social, in the presence of signs and tools. Tools are defined as a means of external activity for humans to influence objects in the environment. An object is defined by Engeström (2009), in his interpretation of Vygotsky's legacy, as any focus of attention; examples might be a hammer, nails, a pencil and dice. Signs are means of internal activity that affect humans internally, such as languages, various systems for counting, algebraic symbol systems and drawings. The drawing in Figure 2 (in which a child is sharing two pizzas between six people) is an example of signs. Vygotsky (1978) believed that the most essential difference between signs and tools are the ways in which they orient human behaviour. A tool's function is externally oriented: "a means by which human external activity is aimed at mastering nature" (p. 55). A sign, on the other hand, is internally oriented: "a means of internal activity aimed at mastering oneself" (p. 55). Theoretically, the tools and signs are perceived as mediating between the participants, such as students, mathematics, and teachers (Bartolini Bussi \& Mariotti, 2008).

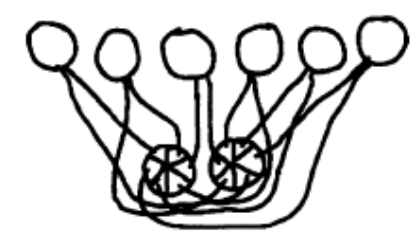

Figure 2. Example of signs in a child's drawing (Empson, 1999, p. 315)

In order to better explain the difference between signs and tools, I use the drawing set out in Figure 2. A child has used a tool (in this case, a pencil) to manipulate an object in the environment (a paper). This action is externally oriented. However, the drawing itself produces an internalization of a mathematical concept, an action that is internally oriented. In this example, the pencil is a tool and the drawing is a sign. This drawing, however, does not merely represent lines and circles, nor does it merely represent a paper and the traces of a pen. Much more importantly, this drawing represents two pancakes that are being divided among six people while mediating the child's mathematical actions in thinking about and solving the problem posed to her (Abtahi, 2016).

How exactly do tools and signs connect individuals and their social worlds? From a Vygotskian lens, this connection can be found in the mere fact that tools and signs cannot be separated from the cultural historical meanings given to them by others in their social worlds of webs of interactions. Traces of thoughts, motivations, knowledges and the existence of others are inherent parts of any sign or any tool that we use in our social lives. Through our conscious and unconscious interactions with social and cultural tools and signs, we grow into the culture and intellect of the life of those around us (Vygotsky, 1978). Utilizing Vygotsky's view, this is how the presence of tools and signs can help us better understand and conceptualize Marx and Engels' view that our very existence is social. Now, if we assume that our very existence is social, how would we 
conceptualize individual learning in this social world? This question leads us to consider the fundamental presence of the more knowledgeable others.

\subsection{Presence of more knowledgeable others}

Vygotsky defined the ZPD as the distance between the independent problem solving and the level of problem solving under adult guidance or in collaboration with more capable peers (Vygotsky, 1978; Lerman \& Meira, 2001). He developed the ZPD because of his interest in how a child can develop into what they have not yet become. According to Wertsch (1985), it is in connection with the ZPD concept that Vygotsky constructed his ideas about the relationship between oneself (intra-psychological) and others (interpsychological). Wertsch argued that the ZPD is "a dynamic region of sensitivity in which the transition from inter-psychological to intra-psychological can be made" (p. 34). This transition from the inter-psychological to the intra-psychological plane is called internalization or learning. Internalization, as described by Vygotsky (1978), is the "process of construction of individual knowledge as generated by socially shared experiences" (p. 56). Lerman (2013) stated that the ZPD is "the mechanism through which learning happens" (p. 22). Now I illustrate these discussions with an example from Empson's (1999) study, in which Sally, Jonathan and Ms. K were discussing the relationship between two eighths and a quarter:

Jonathan: But two eighths make a quarter.

Ms. K: Why? [to Jonathan] Why do you think two eighths make a quarter?

Jonathan: Because eighths are pretty small, and quarters are kind of small, so eighths, if you put them together, you would get a quarter.

Sally: $\quad$ See, look. Here's a fourth [drawing Figure 3(a)].

Sally: [Drawing Figure 3(b)] Here's an eighth. And you want to make a fourth, right? All you have to do is erase four [erases the four lines that halve each fourth]. All you have to do is erase the four lines, to get to fourths, eighths can turn into fourths [drawing Figure 3(c)]. (p. 321)

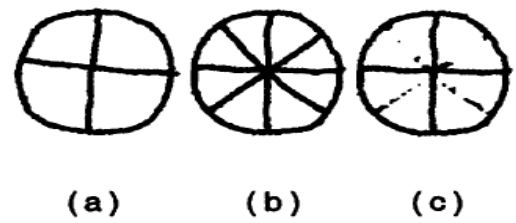

Figure 3. Drawings in Empson (1999, p. 321)

As Empson explained:

After Sally's explanation, Ms. Kolan demonstrated equivalence of [two eighths to one fourth], by cutting up giant paper cutouts [...] At each step, she prompted children to tell her what she was doing or asked a child to remind the group of the conjectures they were checking. (p. 321)

Jonathan's initial explanation of the relationship between $2 / 8$ and $1 / 4$ might show his level of potential development. Based on Vygotsky's theory, the guidance that is provided by Sally and Ms. Konal helped Jonathan to do the following: construct knowledge as generated by socially shared experiences, learn the concept, and consequently solve similar problems in other tasks independently (i.e., the level of actual 
development). The above discussions illustrate that, from a Vygotskian perspective, learning is not possible without the presence of mediating agents (social interactions of any kind). Figure 4 represents the mediating role of social interaction, and the ZPD concept as a space for learning.

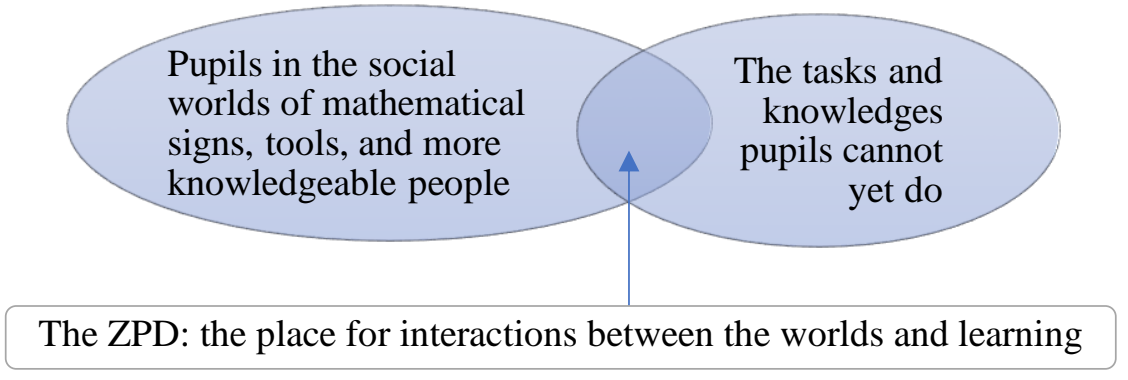

Figure 4. Representation of interactions within ZPD

Pupils live and interact in social worlds of mathematical tools, mathematical signs, and living others with more mathematical knowledge or a different mathematical knowledge. The demand for mathematical growth with the school system says that there are mathematical worlds that pupils cannot interact with simply because they do not know them. The ZPD lies between the worlds of mathematics that pupils can interact with and the worlds of mathematics that they cannot. And the interactions between the worlds, within the ZPD, are impossible without the existence of a more knowledgeable person involved in the activity. The core idea within the concept of the ZPD is that with more capable peers or teacher assistance, students are able to operate at a higher level than they could on their own, and this enables them to learn to become mathematically independent.

Interpreters of Vygotsky have made it clear that others play a major role in children's learning. Rogoff (1990) recognized this significance by stating that children's cognitive development is understood only as taking place with social support in interaction with others, and in the presence of "sociohistorically developed tools that mediate intellectual activity" (p. 35). In this line of thinking, Van Oers (1996) argued that:

One of the basic tenets of the Vygotskian approach to education is the assumption that individual learning is dependent on the social interaction. However, it should be clear from the outset that this is not merely a statement of correlation between individual learning and social context [with others]. This thesis should be interpreted in its strongest possible form, proposing that qualities of thinking are actually generated by the organizational features of the social interaction. (p. 2)

Within our field of mathematics education, the role of the more knowledgeable others has been conceptualized in various degrees and from a variety of theoretical lenses. Roth \& Radford's (2010) conceptualisation of the ZPD is as a zone of interaction that allows all classroom participants to become teachers and learners (p. 305), away from any institutional and/or societal setting (e.g. teachers versus students, or parents versus children). Hence, this role is not limited to those who are adults or sources of authority. Instead, the role of the more knowledgeable others is viewed as alternating between the child and the adult or the child and another child, making the various participants alternately teachers and learners. Goos, Galbraith and Renshaw (2002) refer to such alternation of who is the knowledgeable as bi-directional. Abtahi (2017a) proposes extending interactions within the ZPD to be sign- and/or tool-mediated, in order to extend the notion of the more knowledgeable other to include the resources provided by physical 
properties. Abtahi et al. (2017) more recently refer to such alternation as multi-directional.

All these diverse conceptualisations of the ZPD (as alternating, bi-directional or multi-directional) are focused on the children's mathematical learning. Yet, if a fundamental idea within the ZPD is the existence of more capable people and teachers, then within this view of learning, what is the power that relies on the side of the teachers, and leading to what ethical responsibility?

\section{Part 2 - Vygotsky, Teaching and Teachers}

Let us go back to Marx and Engels' belief that our "own existence is a social activity". The ZPD offers a concept for understating the act of learning within other social activities. As mentioned above, for social theorists such as Vygotsky and followers, learning only happens with the presence of others. In this respect, the ZPD offers crucial contributions to thinking about learning in education, but there is much room to investigate its implications for teachers. In this second part of the article, I aim to highlight a number of issues around the power of teachers and their ethics and responsibility in children's ZPDs, given the theoretical assumption that without their existence children will not be able to move from the level at which they cannot do mathematics independently to a level at which they can. In the following, I first explain how I see the involvement of the act of teaching within the ZPD. I then open up a discussion around conceptualizing teachers' ethical responsibilities. My guiding question in this section is: If our own and our students' very existence is social, as (mathematics) educators, with the power that we have in our classrooms, what do we owe our students? And, more specifically, within the ZPD, what is our ethical responsibility for their mathematical learning and development?

If learning and development within the ZPD means to move from problem solving under the guidance of a more knowledgeable person to independent problem solving, then teaching could be conceptualized as guiding students to do more independently. This means guiding a student to work on a task, for example solving the addition of two fractions, within their ZPD, so that they will eventually learn to add two fractions on their own. The ZPD here has multiple dimensions of significance for the teachers and teaching. Three of these dimensions are:

1. to recognise and be attuned to the students within their ZPDs;

2. to recognise what mathematical concepts are within students' ZPD: not too simple to be solved independently and not too difficult to be beyond their reach; and

3. to be aware of their own crucial existence within the ZPD.

All these dimensions are simple to be written and extremely difficult to recognize and act upon in the day-to-day of mathematics classroom practices. I refer to these dimensions as complex because at times, even students' themselves are not aware of their own ZPDs, what they know, what they need to know or when they need guidance. Despite the complexity, as mathematics educators, it is in the root of teaching practice to be mindful of these dimensions, specifically the third one.

\subsection{Dimensions 1 and 2}

Countless studies in our field have researched dimensions 1 and 2, either separately or jointly, in outlining students' mathematical interactions within the ZPD, conceptualizing the ways in and the extent to which students use the guidance of more 
knowledgeable people or things to enable them to do mathematics independently. For example, in human-social interactions in the broader social milieu, Goos et al. (2002) employ the ZPD as a frame for explaining learning as growing participation in a community of practice in mathematics classrooms. The growth in participation serves to investigate children's sense-making and their justifications for ideas and arguments as they engage in various mathematical activities. When the regulation that takes place between individuals becomes internalized to become various forms of self-regulation of thinking, expressing and acting, then the spaces of the ZPD become spaces for challenging and strengthening the ideas of all involved. In human-tool interactions, Abtahi (2017a, 2017b) examines the ZPD from different angles: in children's interactions with tools to suggest that the ZPD can emerge in this interaction, and to suggest that the ZPD can be a tool-mediated zone of guided action and discussion within which children become acquainted with newer historical and cultural forms of expression and reflection, with traces of the history and culture being embedded in people and/or the tools. These aspects of the ZPD are grounded in the assumption of social cooperation and participation in interaction between one individual and one or more others. Figure 5 shows students' interactions with the world of mathematics, within their ZPD.

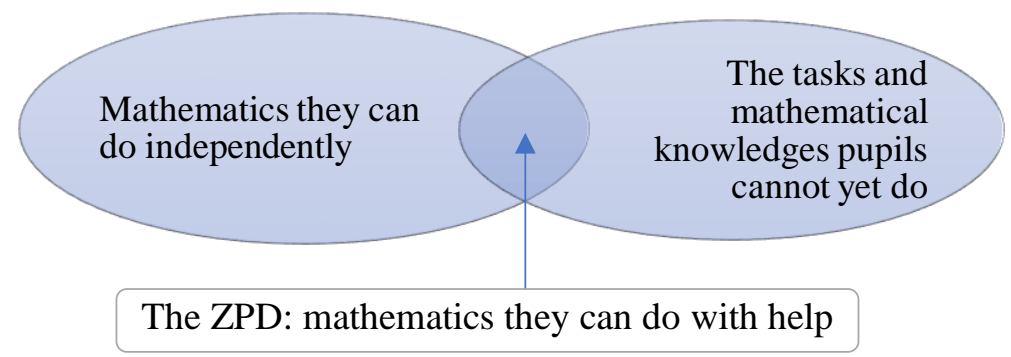

Figure 5. Representation of students' interactions with mathematics and within the ZPD

Common among all these different constructs and uses of the ZPD is the interaction of one with others (a person or people) who provide guidance oriented toward reaching mutually acceptable socially and culturally mediated meanings, such as a mathematical concept.

\subsection{Dimension 3}

Although students' learning within their ZPD has been explored from multiple angles, the exploration of the crucial role and responsibility of teachers with the ZPD (dimension 3 in the abovementioned list) is much less developed. I now navigate and highlight issues around teachers' power and ethical responsibilities, considering the ZPD as a theory of learning. I call it teachers' ethical responsibilities, as opposed to the teachers' role, referring to ethical responsibilities that comes with the power of teachers in classrooms. Once more, I explain what is already conceptualized in the field of mathematics education, and then what I mean by teachers' power, responsibilities and ethics, which is slightly different.

In the specific domain of critical mathematics education, researchers have explored teachers' responsibilities and ethical responsibilities, mainly to discuss the ethical responsibilities of mathematics educators to consider the conflicts and complexities of social, political and ecological topics. Roth (2007) breaks down the word "responsible" and connects the term etymologically to "doing again" (re-), "to pledge" (spondere), and "to be able to" (-ble), arguing that responsibility can be seen as an ability to pledge again, a form of re-engagement with the Other. Atweh and Brady (2009) believe that a focus 
on ethical responsibility can strengthen teachers' professionalism and allow them to make better consideration for students' social and political life worlds. In a more pragmatic frame, Boylan (2016) proposes the relationship with others as one of the principal meanings of an ethical dimension to the mathematics classroom: "[ $t$ ]he relationship to others is, or should be, it is argued, the original ethical form from which societal and institutional relationships are developed" (p. 7). Similarly, Roth (2013) highlights the exposure of both teacher and learner to each other and the role of affect, locating the source of ethical responsibility in answerability and the dialogical nature of learning relationships. In better understanding the term responsibility, Roth (2013) cites the affordance of pairing response (answer) and responsibility (answerability). Boylan's and Roth's views of the relationship to others is the most relevant to the conceptualization of ethics in the ZPD. If within the theoretical perspective of the ZPD, the mathematical learning and development of students is not possible without the existence of teachers, then, considering the level of "answerability and the dialogical nature of learning" ( $p$. 73 ), the teacher's act of teaching would have an inseparable dimension of ethical responsibility.

My view of teachers' ethical responsibilities is slightly different than the ones commented. Overall, mathematics education and mathematics teachers possess power and trust through their positions. It is through this position of power and trust that they have a responsibility towards the common good (D'Ambrosio, 2010). I relate the issue of teachers' ethical responsibilities to the power and trust that is held by the teachers in their classrooms. The common good could have different interpretations. It could include sustainable development, migration, tolerance and understanding of ethnocultural and linguistic diversity, international solidarity. It could also include acting against inequality, polarization and ideological extremism. Within the ZPD, the common good could simply (or not so simply) mean to help as many students as possible, within their ZPD, to learn, develop and move from what they can do with help to what mathematics they can do independently.

Alongside this view of ethical responsibility (through the position of power and trust), there are also responsibilities for the teachers that are mandated by the school system, by the mathematical curricula and by the general society, more broadly. When I, as mathematics educator, enter my classrooms, I carry loads of responsibilities mandated to me, such as the demands of what to teach, when to teach, how to assess the students and even at times the sequences of what to teach first and what resources to use. These are sets of responsibilities that I am accountable for, in the eyes of the education system I work in. Momentarily, I put these system mandated responsibilities in opposition to what I call my ethical responsibility (through my position of power and trust). I do so, because not always, these two kind responsibilities go hand-in-hand and friendly. At times, there are tensions between the two.

Let me give an example of my own inner tensions between my ethical responsibilities and the responsibilities that were demanded of me, from the education system that paid me. In summer of 2019, I taught a Western mathematics pedagogy and content course to a group of Canadian indigenous-perspective teachers. My responsibility, trough the mandates of my job included teaching the content of the provincial mathematics curriculum, ways of teaching an assessing mathematics, and creating templates of lesson plans, as seen appropriate by the official and mandated ministry documents. To be as inclusive as possible to my own culture and those of my students, I carefully thought about my teaching. In my class, I used examples of my own cultural signs and tools. I encouraged my students to do the same, anywhere it made sense to them. Yet, 
upon my daily reflection during my teaching, and much more reflection after my teaching, I became ethically perplexed. I thought, although with all good intentions, I drew on the cultural and historical resources of my students to teach the dominant form of mathematics, but I was still teaching them the dominant mathematics. And I was failing to pay attention to the effects that these taught and learnt mathematics would have had on the integrity and wholeness of the social, cultural and linguistic (re)sources of my students. In my classes, I started to share my ethical worries with my students. We had socio-political conversations about the mandates as well as the limitations of the school system in general. I decided to have these conversations, because as the teacher of the class I deem them appropriate (see Abtahi, in press, for more about this story). In deciding to do so, I was not accountable towards the mandate of the school system. I was only accountable towards my own system of values. My teaching in the summer of 2019 is an example when my responsibilities mandated to me through the education system and my own defined "ethical responsibility as a teacher" became in conflict. With the power that I had and considering my own values, at times, I deemed appropriate to slightly diverge from mathematics and talk about politics of the school system. This, I believe, was my ethical responsibility.

In the mathematics education research literature, I see other examples of consideration of issues of ethical responsibility as expressed in terms of the teachers in the mathematics classroom with students who are exposed to curricular contents that do not represent their cultures in the home (e.g. Civil \& Planas, 2004, and Planas \& Civil, 2009, report the challenges embedded in developing ethical responsibilities with groups of mathematics teachers, educators and researchers around the difficult dialogue in the school institution between the established mathematics and the mathematics of excluded groups). Rather than compiling more examples, nonetheless, I stay close to the conceptual analysis method chosen in this article and revise the concepts behind the example provided by my experience with the teachers throughout the summer course. In this regard, the philosophical views of Roth and Boylan, as I mentioned above, are close to that of Ricœur (1973), and support a more profound understanding. Ricœur explains that the ethics of the relationship between the self and the other, and the formation of one's own self and its self-worth, depend upon one's ability to see oneself as a human being who is called to respond to the other. For Ricœur, it is the demand of the other that determines the formation of the self, and the self is shaped through a lifelong process of accumulating experiences and interpretations. Building on the work of scholars like Roth and Boylan, I extend teachers' ethical responsibility within the ZPD, focusing on Rorty's view of ethics. Rorty states that it is best to think of ethics as a matter of "increasing sensitivity, increasing responsiveness to the needs of a larger and larger variety of people and things" (p. 237). I am influenced by Rorty in my view that ethics forefronts issues of responsibility, as its central priority. To be ethical, we all have to be responsible to each other. Rorty takes this further, to focus on ethics as the responsibilities we have to those who are struggling, are excluded or are just unnoticed. It is exactly this view of ethical responsibility that I believe is fruitful and crucial in thinking about students in their ZPDs -in a zone of their mathematical development in which going forward without a more knowledgeable person is not possible (see Figure 6).

There are two crucial folds related to teaching, in looking at students' ZPD through Rorty's view of ethical responsibility. The first fold is about increasing sensitivity, and the second fold is about the boundaries of school systems. Firstly, when referring to ethics, Rorty talks about increasing sensitivity, specially towards those who are struggling, are excluded or are just unnoticed. Strictly following the theoretical belief of ZPD, 
we could agree that without a person who knows, children will not mathematically develop. This theoretical agreement creates ethical responsibilities to the teachers, to become more sensitive to the ZPDs' of the students, because this is the zone that without a hand from the teacher in the classroom, students' mathematical developments and abilities become hindered. ZPD as a zone that one cannot come out of, without help from another, could also be assumed as a zone of positive struggle. Students positively struggle to learn and develop to solve mathematical problems independently, and it could be teachers' ethical responsibility to make sure that they are excluded or merely unnoticed.

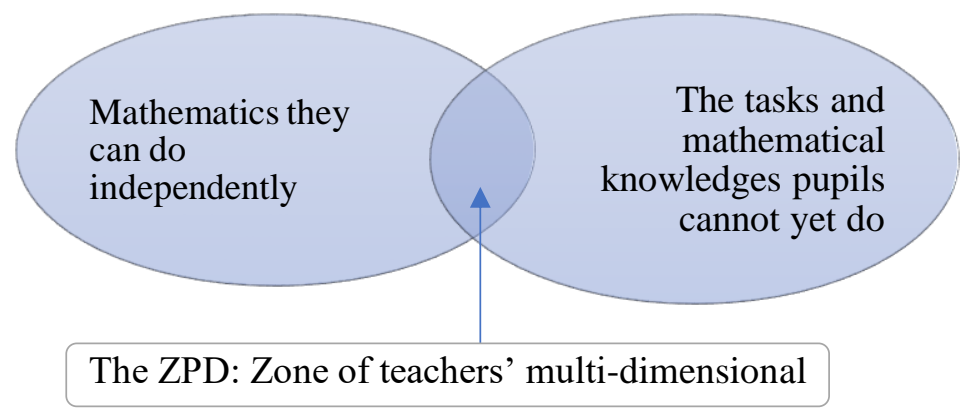

Figure 6. Representation of a focus on teachers' ethical responsibility

The second fold in relating teaching ZPD to teachers' ethical responsibility is a general view of educational systems. Within worldwide, government-supported education systems, students of the same age and relatively similar mathematical knowledge are put into one space. This means that teachers are predominantly and evidently the "more knowledgeable person." Just the mere fact that there are not "others" who are more knowledgeable in the classroom, could create another sense of ethical responsibility for them. Again, strictly following the theoretical belief of ZPD, if the children can only move to a level of independent problem solving with a hand of a person that knows more, and if the teachers' hand is the only hand in the classroom, then another foundation for ethical responsibility is created. In a life that children grew and learnt in communities with many adults around, this ethical responsibility would have been much less on one person and more distributed, in the community.

\section{Conclusion}

In this article, I provided a conceptual analysis of the Zone of Proximal Development (ZPD) in relation to teachers' ethical responsibilities to their students. My intention was to provide a clearer picture of how the ZPD as a learning theory could lend itself to a deeper understanding of teaching. To do this, I first presented a general view of the ZPD as a learning theory. I then conceptualized the ZPD to its fullest extent, by arguing that if learning is a social activity which happens only in the presence of more knowledgeable others, then the act of teaching carries significant ethical responsibility. Building on the work of previous research, I used Rorty's view to highlight that as an ethical act all we need to be is responsible for each other. And if within the ZPD, students' learning and development only depends on the existence of a more knowledgeable person, then this person becomes ethically responsible for the act of teaching so that students are not excluded or just unnoticed. I explicitly clarified what I meant by ethical responsibilities; as responsibilities we have though the power and trust that is provided to us, as teachers, with which we are accountable to our own value systems, and not restrict that mandates of education systems. I then explain two dimensions that solidifies my view of ethical responsibilities of teaching, with the ZPD. If we agree to follow the 
theoretical view of ZPD as a state in which students need guidance from a more knowledgeable person to be able to solve problem independently, then assuming to predominantly be "that knowledgeable person" could create a sense of ethical responsibility. Secondly, if we follow Rorty and assume ethics as increasing sensitivity to the struggles of others, ZPD again becomes a state creating a sense of ethical responsibility, because it is the zone that children cannot come out of, without guidance from others.

I finish the text by acknowledging the delicate and highly complex network of interrelations within the students ZPD. The complexity with the ZPD could come from multiple sources, for example, there fact that not only the teachers, but also the students themselves at times do not know they need guidance, or if they do, they do not ask for it; or the fact that there is only one teacher and many students with many times and spaces of ZPDs, and attending and attending to all students are not easy task; or, the loads of administrative mandates that are asked from the teachers makes the noticing of ZPDs of students more challenging. I acknowledge this challenge. Yet I invite us to think about ZPD as zone of ethical responsibilities for the teacher. After all, we as teachers possess power and trust through our positions.

\section{References}

Abtahi, Y. (in press). What if I was harmful? Reflecting on the ethical tensions associated with teaching the dominant mathematics. Educational Studies in Mathematics.

Abtahi, Y. (2016). Things kids think with: The role of physical properties of the mathematical tools in children's learning (of the addition of fractions). University of Ottawa Publishing. 1-201. https://ruor.uottawa.ca/bitstream/10393/35265/1/Abtahi_Yasaman_2016_Thesis.p $\underline{\mathrm{df}}$

Abtahi, Y. (2017a). The 'more knowledgeable other': A necessity in the zone of proximal development? For the Learning of Mathematics. 37(1), 20-24. https://doi.org/10.1080/14794802.2017.1390691

Abtahi. Y. (2017b). Children, tools and the zone of proximal development. Research in Mathematics Education, 20(1), 1-13. https://doi.org/10.1080/14794802.2017.1390691

Abtahi, Y., Graven, M., \& Lerman, S. (2017). Conceptualising the more knowledgeable other within a multi-directional ZPD. Educational Studies in Mathematics, 96, 275-287. https://doi.org/10.1007/s10649-017-9768-1

Atweh, B., \& Brady, K. (2009). Socially response-able mathematics education: Implications of an ethical approach. Eurasia Journal of Mathematics, Science \& Technology Education, 5(3), 267-276. https://doi.org/10.12973/ejmste/75278

Bartolini Bussi, M. G., \& Mariotti, M. A. (2008). Semiotic mediation in the mathematics classroom: Artefacts and signs after a Vygotskian perspective. In L. D. English, \& D. Kirshner (eds.), Handbook of international research in mathematics education (pp. 746-783). Routledge.

Boylan, M. (2016). Ethical dimensions of mathematics education. Educational Studies in Mathematics, 92, 395-409. https://doi.org/10.1007/s10649-015-9678-z 
Burbules, N. C., \& Warnick, B. R. (2006). Phylosophical inquiry. In J. L. Green, G. Camilli, \& P. B. Elmore (eds.), Handbook of complementary methods in education research (pp. 489-502). Routledge.

Civil, M., \& Planas, N. (2004). Participation in the mathematics classroom: Does every student have a voice? For the Learning of Mathematics, 24(1), 7-12.

Cole, M., John-Steiner, V., Scribner, S., \& Souberman, E. (1978). Biographical note on L. S. Vygotsky. Mind in society the development of higher psychological processes (pp. 1-15). Harvard University Press.

D'Ambrosio, U. (2010). Mathematics education and survival with dignity. In H. Alrø, P. Valero, \& O. Ravn (Eds.), Critical mathematics education: Past, present and future (pp. 51-63). Brill/Sense. https://doi.org/10.1163/9789460911644_006

Empson, S. B. (1999). Equal sharing and shared meaning: The development of fraction concepts in a first-grade classroom. Cognition and Instruction, 17(3), 283-342. https://doi.org/10.1207/S1532690XCI1703_3

Engeström, Y. (2009). The future of activity theory: A rough draft. In A. Sannino, H. Daniels, \& K. D. Gutiérrez (eds.), Learning and expanding with activity theory (pp. 303-328). Cambridge University Press. https://doi.org/10.1017/CBO9780511809989.020

Goos, M., Galbraith, P., \& Renshaw, P. (2002). Socially mediated metacognition: Creating collaborative zones of proximal development in small group problem solving. Educational Studies in Mathematics, 49, 193-223. https://doi.org/10.1023/A:1016209010120

Lerman, S. (2013). Learning and knowing mathematics. In P. Andrews, \& T. Rowland (eds), Masterclass in mathematics education: International perspectives on teaching and learning (pp. 15-26). Bloomsbury. https://doi.org/10.5040/9781350284807.ch-002

Lerman, S. \& Meira, L. (2001). The zone of proximal development as a symbolic space. South Bank University, Faculty of Humanities and Social Science.

Marx, K., \& Engels, F. (1988). Economic and philosophic manuscripts of 1844 and the Communist Manifesto [Trans. M. Milligan]. Prometheus. (Original work published 1930)

Planas, N., \& Civil, M. (2009). Working with mathematics teachers and immigrant students: An empowerment perspective. Journal of Mathematics Teacher Education, 12(6), 391-409. https://doi.org/10.1007/s10857-009-9116-1

Ricœur, J. P. G. (1973). Ethics and culture. Philosophy Today, 17(2), 153-165. https://doi.org/10.5840/philtoday197317235

Rogoff, B. (1990). Apprenticeship in thinking: Cognitive development in social context. Oxford University Press.

Rorty, R. (2009). Philosophy and the mirror of nature. Princeton University Press. https://doi.org/10.1515/9781400833061

Roth, W.-M. (2007). Solidarity and the ethics of collaborative research. In S. Ritchie (ed.), Research collaboration: Relationships and praxis (pp. 27-42). Sense Publishers. https://doi.org/10.1163/9789087903138_004 
Roth, W.-M. (2013). Toward a post-constructivist ethics in/of teaching and learning. Pedagogies. An International Journal, 8(2), 103-125. https://doi.org/10.1080/1554480X.2013.767769

Roth, W.-M. (2018). A transactional approach to research ethics. Forum: Qualitative Social Research, 19(3), 100-112

Roth, W.-M., \& Radford, L. (2010). Re/thinking the zone of proximal development (symmetrically). Mind, Culture and Activity, 17(4), 299-307. https://doi.org/10.1080/10749031003775038

Van Oers, B. (1996). Learning mathematics as a meaningful activity. In L. P. Steffe, P. Nesher, P. Cobb, G. A. Goldin, \& B. Greer (eds.), Theories of mathematical learning (pp. 91-113). Routledge.

Vygotsky, L. S. (1978). Mind in society: The development of higher psychological processes [Eds. M. Cole, V. John-Steiner, S. Scribner, \& E. Souberman]. Harvard University Press.

Walshaw, M. (2017). Understanding mathematical development through Vygotsky. Research in Mathematics Education, 19(3), 293-309. https://doi.org/10.1080/14794802.2017.1379728

Wertsch, J. V. (1985). Vygotsky and the social formation of mind. Harvard University Press.

Yasnitsky, A., \& Van der Veer, R. (eds.) (2015). Revisionist revolution in Vygotsky studies: The state of the art. Routledge. https://doi.org/10.4324/9781315714240

\section{Reference of the author}

Yasmine Abtahi, University of South East Norway, Yasmine.Abtahi@usn.no 


\title{
A theoretical exploration: Zone of Proximal Development as an ethical zone for
}

\section{teaching mathematics}

\author{
Yasmine Abtahi, University of South East Norway
}

Marx-based socio-cultural theory of Vygotsky situates learning within pupils' interactions with the other humans and non-humans. In this article, I speak about the Zone of Proximal Development (ZPD) which is one of many other Vygotskian concepts such as mediation and internalization. Together with providing a thorough description of some key aspects of Vygotsky's theoretical concepts, through the major question stated, What are the ethical responsibilities of teachers to guide students do mathematics that is beyond their independent ability? the article intends to open up an original line of inquiry. The ZPD has been utilized for decades to theorize students learning. Yet, not much attention is paid to teachers' responsibilities within the ZPD. I will explore how the very nature of the ZPD assumes ethical responsibilities for the teachers. First, I explain the ZPD within the networks of other concepts in socio-cultural theory. Then, I elaborate what I mean by ethical responsibilities and finally I highlight how I see ZPD as a zone of teachers' multi-dimensional ethical responsibility. In a belief that human's exitance is social, Vygotsky developed his learning theory. He probably thought: what is the relationship between being inherently social and learning. In such endeavor, the ZPD is described by Vygotsky as "the distance between the actual developmental level (independent problem solving) and the level of potential development (problem solving under adult guidance or in collaboration with more capable peers)" (Vygotsky, 1978, p. 69). The concept of ZPD makes the connection between learning and society explicit as it refers to the need for the presence of another more competent person in any learning. So, if learning can only happen with the presence of a more knowledge person, and if more often than not the more knowledge person is assumed to be the teacher, then does ZPD become a zone of ethical responsibility for the teacher? For me, as teacher ethical responsibility is not only what is demanded of me as part of the mandates of my teaching job, but also the responsibilities that I demand from myself, based on my system of values. In this matter, I align myself with Rorty to think of ethics as a matter of "increasing sensitivity, increasing responsiveness to the needs of a larger and larger variety of people and things" (p. 237). This view of Rorty is what I mean by our (i.e., teachers) ethical responsibility. But how this related to the ZPD? Strictly following the theoretical belief of ZPD, we could agree that without a person who knows, children will not mathematically develop. Hence ethical responsibilities of the teachers are to become more sensitive to the ZPDs' of the students, because this is the zone that without help students' mathematical abilities become hindered. Secondly, teachers are often the adults in the classroom that know (school mathematics). Just the fact that there are not "others" who are more knowledgeable in the classroom, could create another sense of ethical responsibility for them. After all, we are teachers and we possess power and trust through our positions. 